\title{
Perancangan E-Commerce Penunjang Promosi Dan Penjualan PT. Emsada Cipta Lestari Di Bekasi
}

\author{
Wahyu Subono ${ }^{1}$ \\ Program Studi Akuntansi \\ Universitas Mohammad Husni Thamrin \\ wahyusubono@gmail.com
}

\author{
Sugih Prihatin ${ }^{2}$ \\ Program Studi Teknik Informatika \\ Universitas Mohammad Husni Thamrin \\ sugihprihatin70@gmail.com
}

\begin{abstract}
Abstrak - Penelitian ini bertujuan untuk meningkatkan efisiensi dan efektifitas dalam usaha pencapaian omset atau pendapatan perusahaan yang maksimal melalui penerapan e-commerce untuk menunjang promosi dan penjualan.

Metode yang digunakan dalam penelitian ini adalah metode pengembangan dengan teknik deskriptif analisis kualitatif. Alat pengumpulan dan perekaman data penelitian ini berupa wawancara kepada karyawan dan pemilik perusahaan.

Temuan penelitian dari hasil analisis data menunjukkan bahwa E-commerce sesuai dengan kebutuhan pasar saat ini. E-commerce menjadi solusi yang efektif dan efisien untuk penjualan alat-alat pertambangan untuk pasar retail, yang sangat berguna untuk perusahaan.
\end{abstract}

Kata Kunci: E-commerce, Promosi, Penjualan

\section{PENDAHULUAN}

Kemajuan Teknologi Informasi merupakan salah satu pemicu terjadinya perubahan proses untuk dapat memperoleh informasi secara cepat dan akurat. Teknologi Informasi mempunyai pengaruh yang besar dalam berbagai aspek kehidupan masyarakat, baik dalam dunia usaha, pemerintahan, pendidikan, kesehatan serta kebutuhan-kebutuhan harian masyarakat lainnya.

Informasi ini tidak lagi di sajikan secara manual namun di kemas secara digital untuk berbagai keperluan. Internet sebagai salah satu media teknologi informasi sangat besar manfaatnya bagi masyarakat yang membutuhkan informasi tanpa terhalang oleh jarak dan perbedaan waktu yang sebelumnya menjadi penghambat dalam penyebaran informasi.

Internet merupakan media informasi yang sangat cepat dan efisien dalam penyebaran informasi, dan keberadaan media ini telah membentuk budaya masyarakat yang baru. Untuk mencari informasi di internet dapat dilakukan dengan mengunjungi situs (website) yang berhubungan dengan informasi yang dibutuhkan atau dapat dilakukan pencarian di situs pencari (Search Engine Site's) seperti google. Perkembangan internet yang sangat pesat membawa banyak perubahan bagi dunia usaha secara keseluruhan. Sarana teknologi mendorong sistem penjualan yang lebih menarik. Banyak perusahaan baik di dalam dan di luar negeri yang sudah menggunakan internet sebagai sarana pendukung promosi dan penjualan secara online.

Website merupakan salah satu aplikasi pada internet yang berupa informasi hypertext, dimana pemakai dapat membaca dan menelusuri informasi tersebut secara virtual tanpa terikat pada media tertentu. Melalui website kita dapat memasarkkan produk atau jasa, mempromosikan suatu perusahaan, dan lain-lain. Berdasarkan hal tersebut maka dirasa perlu untuk membuat website penjualan online yang bertema Emsada Online Shop.

PT. Emsada Cipta lestari sebagai perusahaan pembuat desain dan distributor suku cadang alat berat belum memanfaatkan internet sebagai media untuk mengenalkan perusahaan dan produk-produk yang di buat oleh perusahaan tersebut. Hal ini dikarenakan belum adanya sumber daya manusia yang dapat melakukan hal tersebut. Dengan persaingan yang cukup ketat saat ini di dunia usaha yang bergerak di bidang karoseri dan pembuatan alat-alat pertambangan maka sangat di butuhkan alat bantu penjualan yang efektif dan menarik. Oleh karena itu perlu diterapkan konsep ecommerce untuk mendukung promosi dan penjualan PT Emsada cipta lestari.

Manfaat yang ingin dicapai dalam menggunakan E-Commerce pada penelitian ini adalah:

1. Melebarkan jangkauan (global reach).

Dengan Transaksi on-line yang dapat diakses oleh semua orang di dunia tidak terbatas tempat dan waktu karena semua orang dapat mengaksesnya hanya dengan menggunakan media perantara komputer.

2. Meningkatkan kesetiaan konsumen. 
Kesetiaan konsumen menigkat karena sistem transaksi E-Commerce menyediakan informasi secara lengkap dan informasi tersebut dapat diakses setiap waktu selain itu dalam hal pembelian juga dapat dilakukan setiap waktu.

3. Mempersingkat waktu pembelian

Dengan konsep E-Commerce pemesanan dapat dilakukan dengan waktu singkat tanpa perlu lagi telpon ke bagian penjualan atau datang langsung ke perusahaan.

\section{METODE PENELITIAN}

E-commerce merupakan prosedur berdagang atau mekanisme jual-beli di internet dimana pembeli dan penjual dipertemukan di dunia maya. E-commerce juga dapat didefinisikan sebagai suatu cara berbelanja atau berdagang secara online atau direct selling yang memanfaatkan fasilitas Internet dimana terdapat website yang dapat menyediakan layanan "get and deliver" akan merubah semua kegiatan marketing dan juga sekaligus memangkas biaya-biaya operasional untuk kegiatan trading (perdagangan).

Proses yang ada dalam Ecommerce adalah sebagai berikut:

1. Pembuatan Website untuk produk dan layanan.

2. Pemesanan secara langsung dan tersedianya tagihan.

3. Otomasi account Pelanggan secara aman

4. Pembayaran yang dilakukan secara langsung (online) dan penanganan transaksi mengenal lawan komunikasi, maka jenis informasi yang dikirimkan dapat disusun sesuai dengan kebutuhan dan kepercayaan (trust).

Prosedur sistem yang diusulkan untuk Ecommerce PT. Emsada Cipta Lestari di buat lebih efisien dan sederhana untuk mempermudah dan mempercepat proses pembelian, adapun prosedur system usulan nya adalah sebagai berikut:

1. Pendaftaran

Konsumen melakukan registrasi pendaftaran pada sistem agar konsumen memiliki hak akses untuk memasuki sistem penjualan produk dari Emsada secara online. Konsumen diwajibkan untuk memasukkan Nama user, alamat email , tanggal lahir dan password. Setelah melakukan pendaftaran, konsumen akan mendapatkan notifikasi email yang menyatakan konsumen tersebut sudah terdaftar. Selanjutnya konsumen bisa melakukan login.

2. Pembelian

Konsumen melakukan browsing di internet untuk melihat semua informasi mengenai produk dari
Emsada secara online. Pertama-tama konsumen melakukan login dengan ketentuan registrasi yang telah dilaksanakan di tahap ke-1, melalui menu user agar dapat melakukan proses pemesanan barang. Setelah proses login berhasil, konsumen dapat langsung memesan barang melalui menu "produk" dengan memilih di daftar produk yang akan dipesan berdasarkan stok barang yang tersedia. Klik kolom status "pesan sekarang" dan isi banyaknya barang yang diinginkan. Apabila selesai, klik checkout. Pemesanan dan pengiriman barang segera di proses. Konsumen diharuskan mengisi form alamat kirim sebagai patokan pengiriman barang.

3. Pembayaran

Konsumen dapat melihat status pemesanan di "form pemesanan", sebagai acuan untuk transaksi dan pelanggan boleh langsung mentransfer dana ke rekening yang telah disediakan. Konsumen dapat melakukan pembayaran sesuai dengan pemesanan diatas melalui transfer antar bank. Konsumen pun akan diberikan bukti pembayaran dan dikirimkan notifikasi verifikasi pembayaran.

4. Pengiriman Barang

Staff admin akan memeriksa apakah pelanggan sudah melakukan pembayaran atas barang yang dipesan. Apabila pembayaran sesuai dengan pemesanan maka barang siap dikirim ke alamat pelanggan.

5. Laporan

Admin dapat mengolah seluruh data, laporan informasi mengenai penjualan produk Emsada.

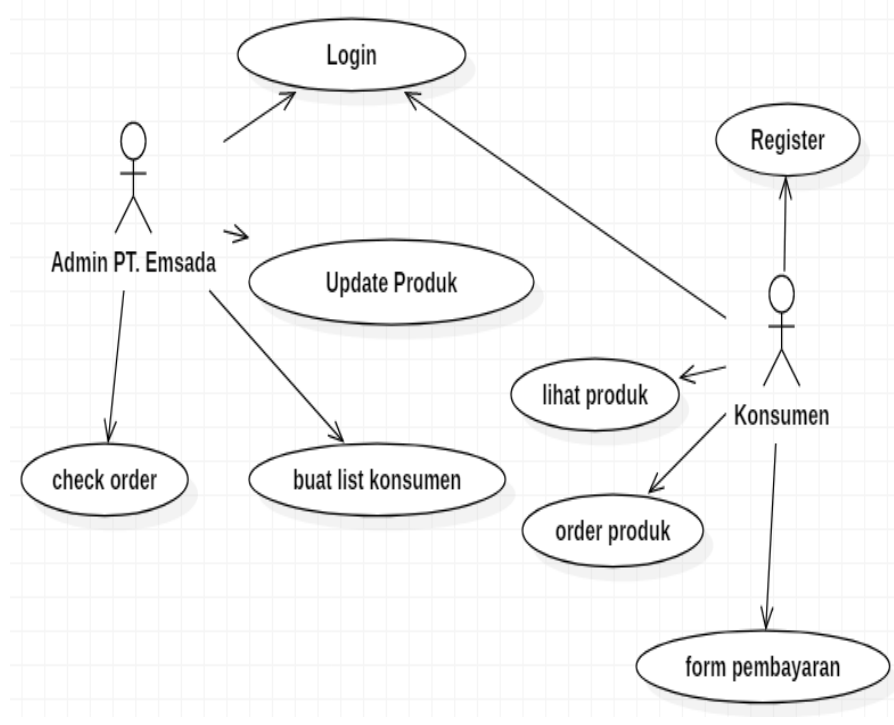

Gambar 1. Use case diagram 


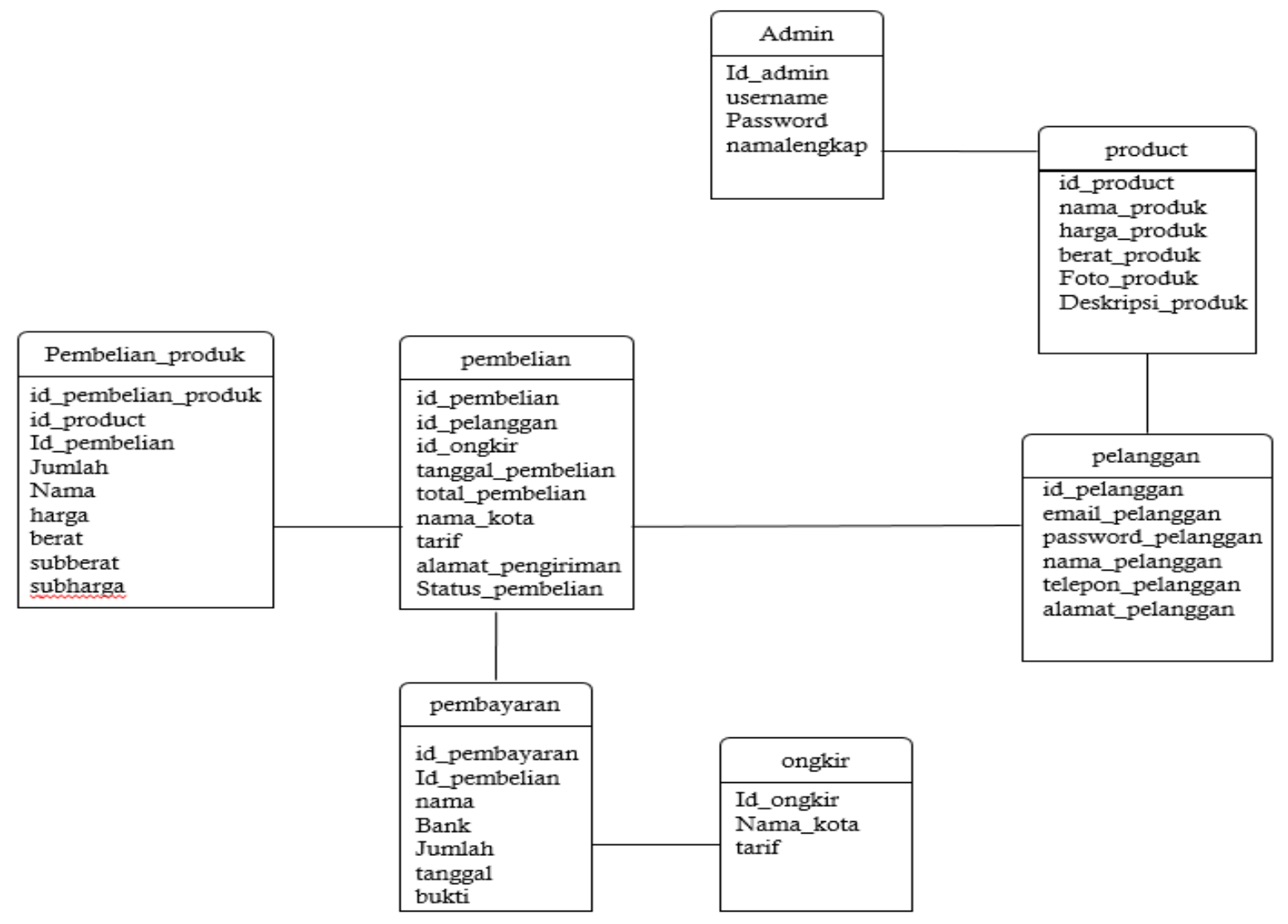

Gambar 2. Logical Relational Structure

ERD merupakan suatu model untuk menjelaskan hubungan antar data dalam basis data berdasarkan objek-objek dasar data yang mempunyai hubungan atau relasi.

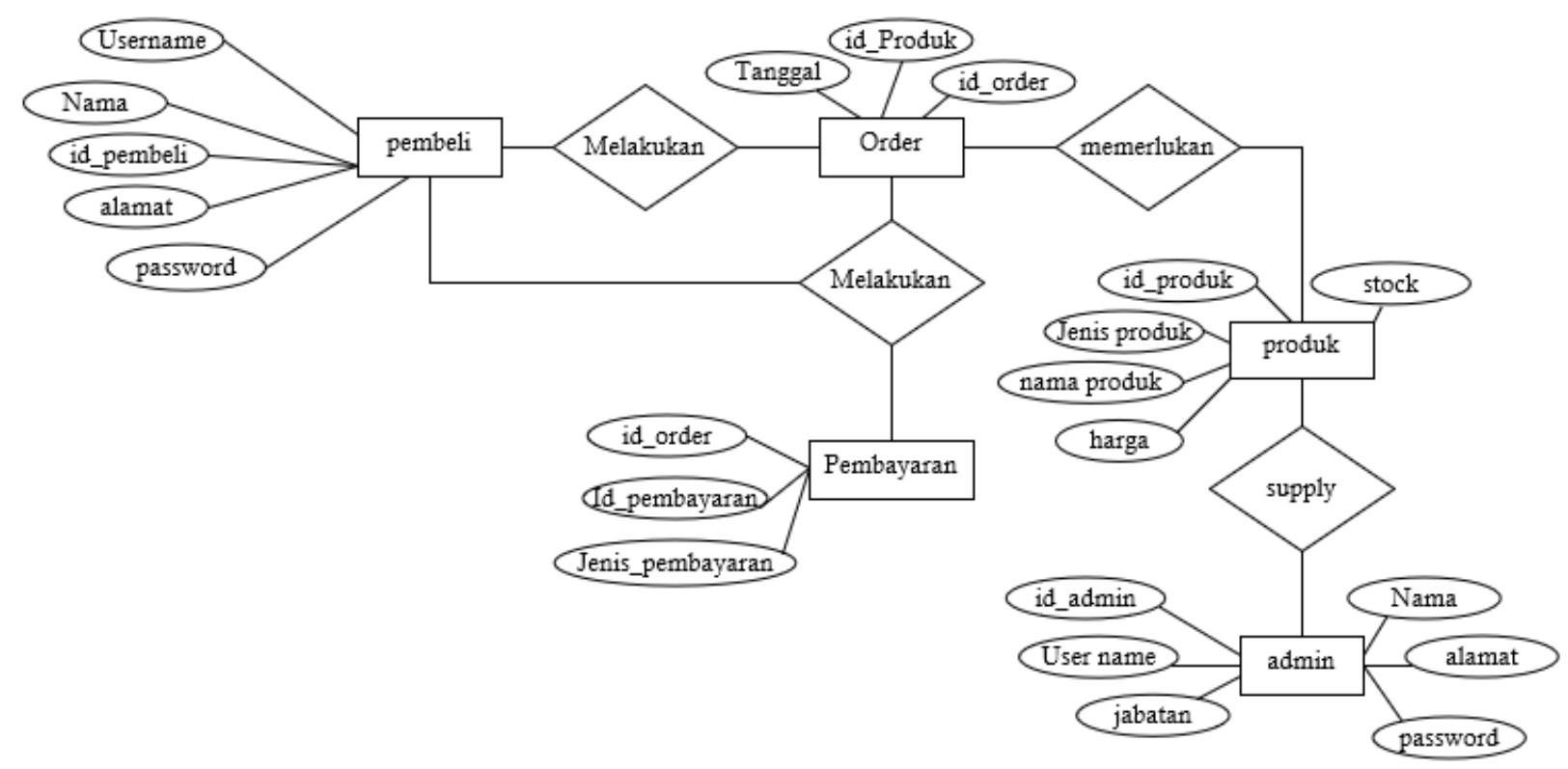

Gambar 3. Entity Relationship Diagram 


\section{HASIL DAN PEMBAHASAN}

Perancangan input diperlukan untuk memasukan data sebagai sumber informasi, dimana perancangan input menghasilkan perancangan bentuk dokumen dasar yang akan digunakan untuk mendapatkan data.

\section{EMSADAONLINE : Login}

( Login yourself to get access )

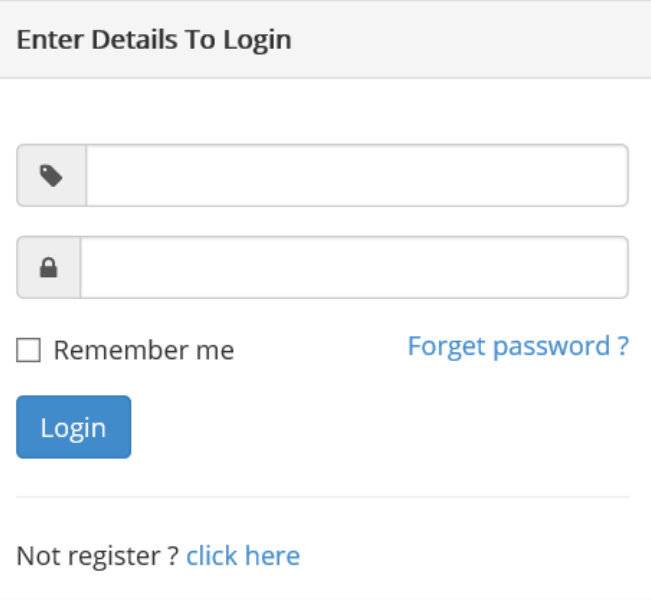

\section{Gambar 4. Form Login Admin}

Ketika melakukan login, seorang admin perlu memasukkan user name dan password. Jika sesorang berusaha masuk ke dalam web admin namun tidak memiliki user name maka akan muncul tulisan "login gagal“" dan kembali ke tampilan awal dari form login admin.

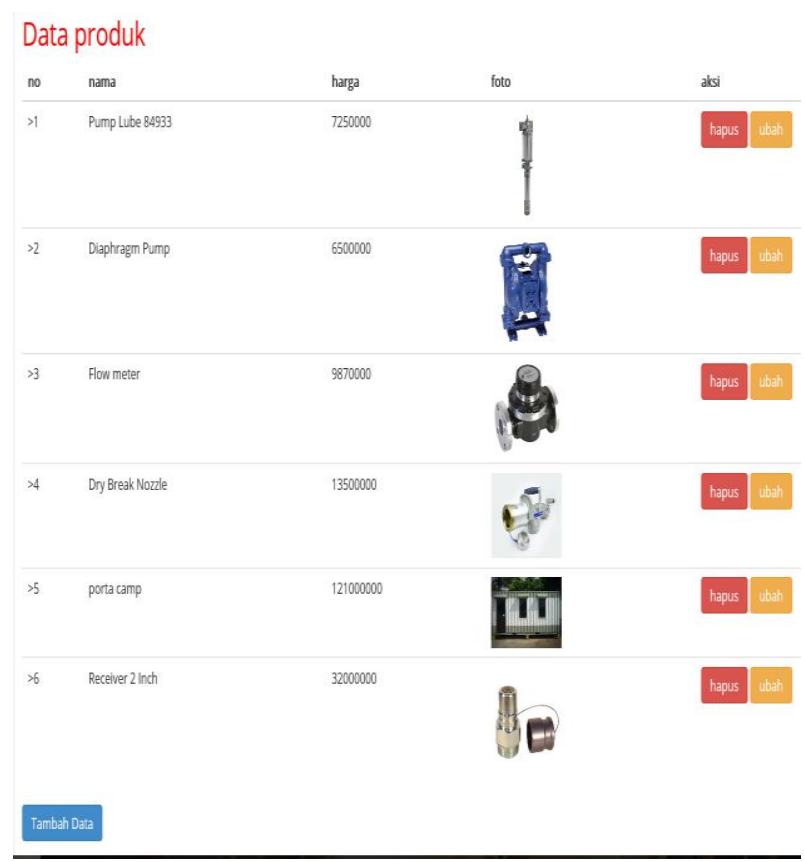

Form input ini di gunakan jika admin ingin menambahkan produk baru atau ada update produk. Form ini menjadi sangat penting karena update produkproduk dan harga terkadang terjadi begitu cepat. Form input produk dimulai dari nama produk, kategori, harga, foto, deskripsi. Setelah data terisi semua langsung klik simpan.

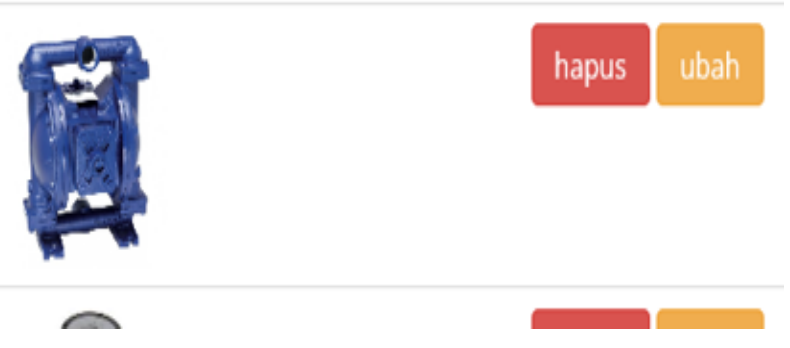

Gambar 6. Form Hapus Produk

Untuk menghapus produk yang sudah tidak valid lagi, cukup menekan tombol hapus pada Data produk.

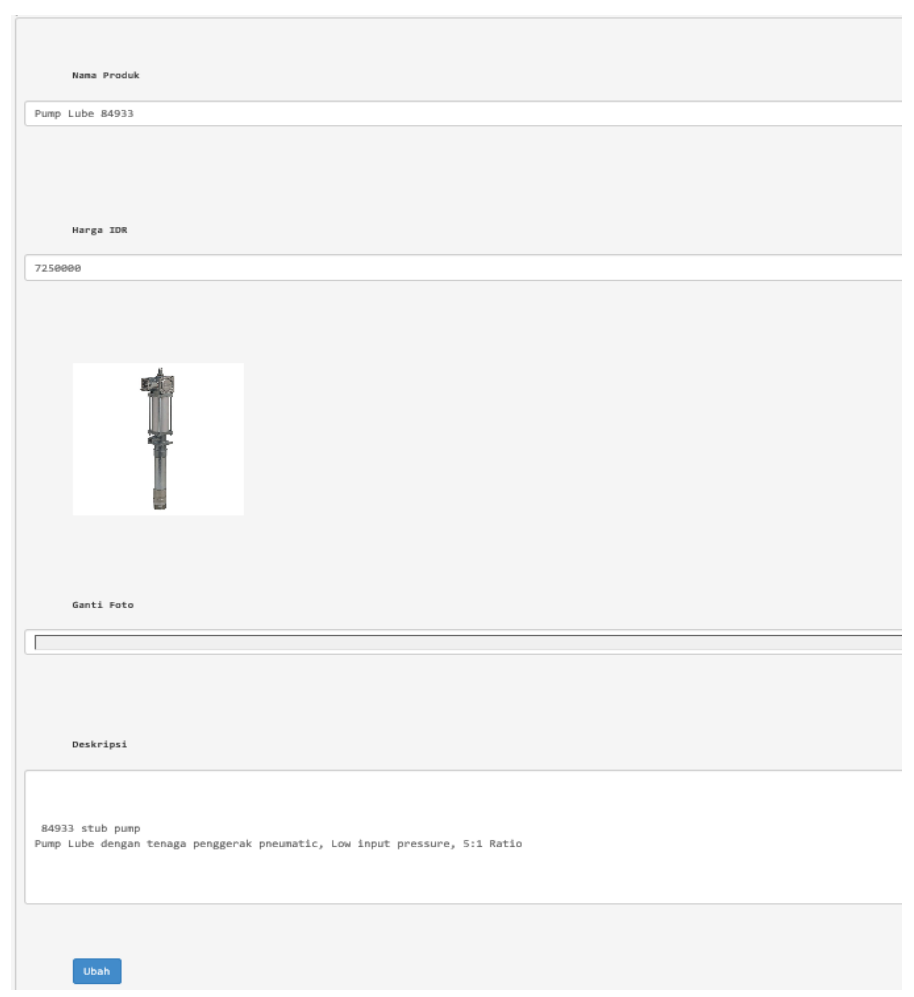

Gambar 7. Form Ubah Produk

Form ubah data berisikan no, gambar, nama produk, kategori dan harga.

Gambar 5. Form Input dan Edit Produk 
Email

Password

Gambar 8. Form Login Pelanggan

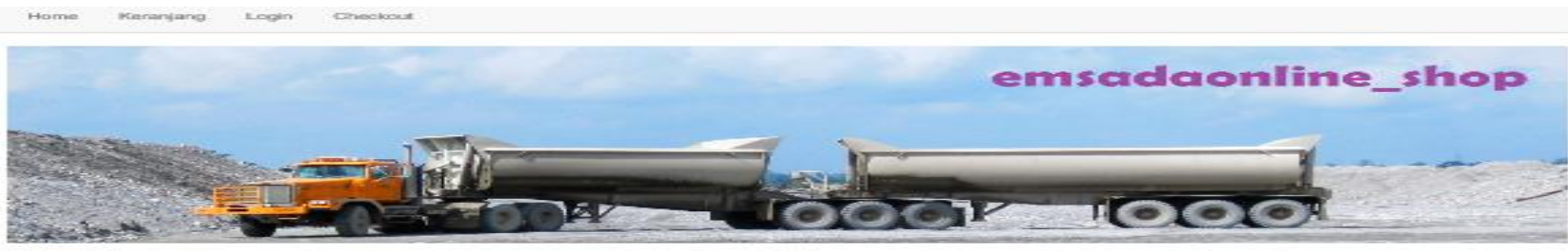

Produk Unggulan
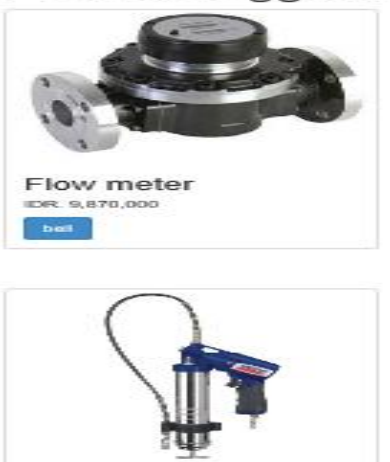

Air P

Der. 1 .

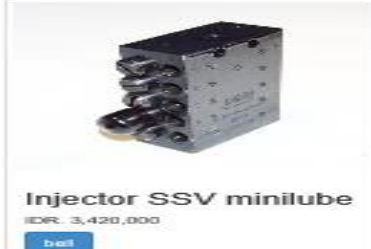

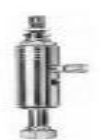

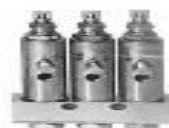

Injector lube 1007. 1.350 .000

bes

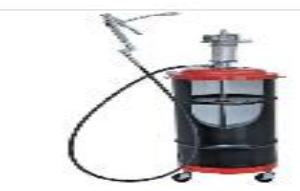

Air operated Power Master pump une. arso, 000

bet

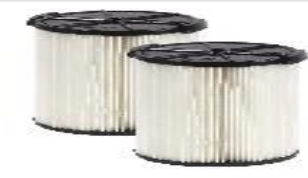

filter elemen une. 3.400 .000

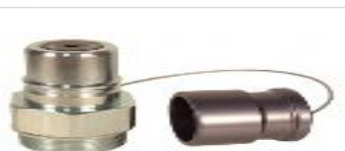

Receiver 2 Inch IDF. $32,000,000$

-

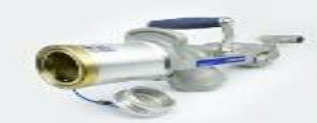

2 Inch Dry Break Nozzle

Ba

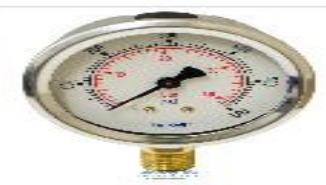

Pressure Gauge IDF. 1.3200000

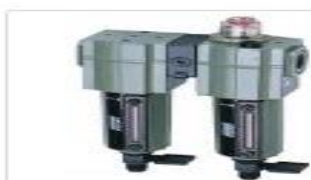

Air Filter iDer. 700,000

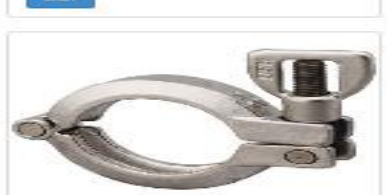

Clar ide seo.00

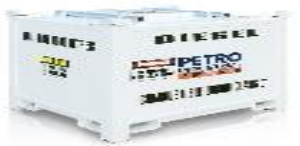

FuelTank 10001 IDFe 18,0000000

Gambar 9. Tampilan situs web E-commerce

Tampilan Home dari situs web E-commerce PT.Emsada Cipta Lestari berisikan produk-produk unggulan dan harganya.
Output merupakan hasil dari pengolahan data setelah suatu masukan lengkap, dan diproses hingga menghasilkan keluaran (Output). Dalam perancangan aplikasi ini yang paling penting adalah output yang dihasilkan harus sesuai dengan keinginan dan kebutuhan pemakai atau User. Adapun tampilan output yang dihasilkan dari perancangan E-commerce PT.Emsada Cipta Lestari ini yaitu sebagai berikut: 


\section{Keranjang Belanja}

\begin{tabular}{lllll} 
No & Produk & Harga & Jumlah & Subharga \\
\hline 1 & Flow meter & IDR. $9,870,000$ & 2 & IDR. 19,740,000 \\
\hline 2 & Receiver 2 Inch & IDR.32,000,000 & 2 & IDR.64,000,000
\end{tabular}

Lanjutkan Belanja Checkout

Gambar 10. Form Output Keranjang Belanja

\section{Detail Pembelian}

\begin{tabular}{|c|c|c|c|c|c|c|}
\hline & elian & Pelanggar & & & Pengirim & \\
\hline & elian : 44 & nugi ridwan & & & Jabodetabek & \\
\hline & 018-07-20 & 081191919392 & & & Ongkos Kirim : & \\
\hline & $2,520,000$ & nugi_ridwan@yal & & & Alamat Pengirin & Raya Bogor KM24 Jakarta \\
\hline no & nama produk & harga & berat & jumlah & subberat & subtotal \\
\hline 1 & Clamp union 2 inch Pipa & IDR. $.560,000$ & $100 \mathrm{Gr}$. & 2 & $200 \mathrm{Gr}$. & IDR.1,120,000 \\
\hline 2 & Air Powered Grease Gun & IDR.1,400,000 & 150Gr. & 1 & 150Gr. & IDR.1,400,000 \\
\hline & elakukan pembayaran II & & & & & \\
\hline
\end{tabular}

Gambar 11. Form Output Faktur Pembelian

\section{KESIMPULAN}

Dengan dirancangnya E-commerce berbasis web penunjang promosi dan penjualan untuk PT. Emsada Cipta Lestari, dapat mempermudah pelanggan dan calon konsumen untuk melakukan pemesanan produk melalui website emsadaonline_shop. Pelanggan tidak harus menunggu kunjungan dari Sales dalam melakukan pemesanan. Aplikasi ini dapat mempermudah pelanggan untuk mengakses informasi terkini mengenai produk produk terbaru dan perubahan harga produk serta ketersediaan produk. 
Untuk memperoleh hasil yang optimal dari Sistem informasi berbasis web sebagai penunjang promosi dan penjualan ini, maka ada beberapa hal yang perlu diperhatikan diantaranya adalah: Perlu dilakukan backup data untuk menjamin keamanan data. Perlu diadakan pemeliharaan sistem secara berkala, misalnya dengan menginstal antivirus, melakukan defragmenter secara periodik, dan lain sebagainya. Sistem penjualan yang tepat menghasilkan pendapatan yang lebih baik. Sistem e-commerce juga berguna sebagai bahan untuk mengambil keputusan terhadap pengembangan suatu produk dan pengembangan market baru. Hendaknya manajemen melakukan evaluasi berkala untuk mengantisipasi penambahan kebutuhan sistem baru serta melakukan update file secara berkala untuk mencegah kejenuhan user.

\section{REFERENSI}

Dixon Matthe dan Brent Adamson. 2015. The Challenger Sale. Portfolia Penguin. London

Jubilee Enterprise. 2017. HTML5 Komplit. PT. Elex Media Komputindo.Jakarta

Marisa Fitri. 2016. Web Programming (Client side and Server Side). CV Budi Utama.Sleman

Mahrus Ali Ahmad.2010. Web design dan Pemograman web. Pranata Indonesia. Jakarta

Madcoms. 2015. Pemrograman PHP \& MySQL dengan Adobe Dream Weaver .PT Gramedia Pustaka Utama. Jakarta

Rahman Su .2017. Kitab SEO pamungkas.PT. Elex Media Komputindo. Jakarta

Subagia Anton. 2018. Membangun Aplikasi web dengan Metode OOP. PT. Elex Media Komputindo. Jakarta

Windusari Heria dan Hyacintha Susanti. 2016. Excellent service the secret of building a service organization. PT Gramedia Pustaka Utama. Jakarta 